\title{
LLUVIA DE SIGLAS EN EL CAMPO: EL SINDICALISMO AGRARIO EN LA PROVINCIA DE VALLADOLID DURANTE LA TRANSICIÓN (1975-1980)
}

Rain of acronyms in the countryside: Agricultural unionism in the province of Valladolid during the Transition (1975-1980)

\author{
JESÚS ÁNGEL REDONDO CARDEÑOSO \\ Universidad de Valladolid \\ jesus.redondo.cardenoso@uva.es
}

Cómo citar/Citation

Redondo Cardeñoso, J. Á. (2020).

Lluvia de siglas en el campo: el sindicalismo agrario en la provincia de

Valladolid durante la Transición (1975-1980).

Historia y Política, 44, 337-368

doi: https://doi.org/10.18042/hp.44.12

(Recepción: 27/11/2019; evaluación: 12/02/2020; aceptación: 12/04/2020; publicación: 27/11/2020)

Resumen

El presente artículo analiza la proliferación de organizaciones profesionales agrarias en Valladolid durante la Transición. Para ello utiliza prensa provincial (El Norte de Castilla) y nacional (El Pais), documentación del Gobierno Civil y algunos testimonios orales de protagonistas de la época. En primer lugar, se realiza un repaso al panorama general del sindicalismo agrario en el país durante el período. Después, el texto se centra en el análisis de los antecedentes, creación y primera evolución de los sindicatos agrarios surgidos en la provincia de Valladolid tras la dictadura franquista, tanto conservadores como progresistas, así como el proceso de integración de estos en la nueva estructura sindical agraria imperante entre 1977 y 1980. El artículo no solo pretende mostrar que la cuenca del Duero vivió una intensa movilización 
sindical agraria durante la Transición, sino también que esa sindicalización agraria fue responsabilidad tanto de sectores progresistas, como de sectores conservadores.

\title{
Palabras clave
}

Sindicalismo; agricultura; Transición; Valladolid.

\begin{abstract}
This article analyses the proliferation of professional agricultural organizations in Valladolid during the Transition. For this, it uses provincial and national press $(E l$ Norte de Castilla, El Pais), documentation of the Civil Government, and some oral testimonies. First, it carries out a brief bibliographic review of the general context of the agricultural unionism in Spain during the studied period. Then, the text analyses the background, creation, and first evolution of the agricultural unions created in the province of Valladolid after the Francoist dictatorship, and the integration of these farmers' associations in the new agricultural trade union structure that existed between 1977 and 1980. The objectives of the article are to show that the farmers from the Duero basin led an intense union mobilisation during the Transition and that that unionisation was driven not only by progressive but also by conservative ideological groups.
\end{abstract}

\section{Keywords}

Trade unionism; agriculture; Transition; Valladolid. 
I. INTRODUCCIÓN. II. LA EVOLUCIÓN DEL PANORAMA SINDICAL DEL CAMPO ESPAÑOL DURANTE LOS AÑOS SETENTA. III. LOS SINDICATOS AGRARIOS CONSERVADORES EN LA PROVINCIA DE VALLADOLID: DEL VERTICALISMO AL SINDICALISMO LIBRE. IV. LOS SINDICATOS AGRARIOS «DE CLASE»EN LA PROVINCIA DE VALLADOLID: DE LA CLANDESTINIDAD A LA LEGALIDAD. V. CONCLUSIONES. BIBLIOGRAFIA.

\section{INTRODUCCIÓN}

El 18 de marzo de 1980 tuvo lugar en Valladolid una manifestación de agricultores y ganaderos. Según la prensa, hasta 15000 manifestantes recorrieron las calles céntricas de la capital pinciana tras una pancarta firmada por siete siglas que pedía "Justicia para el campo» (imagen 1)1. Esas siglas eran AEPA, APAG, AGGR, FTT, S.R., UCV y UGV, y correspondían a diferentes asociaciones profesionales agrarias que, por aquel entonces, existían en la provincia, respectivamente: Asociación Empresarial Provincial Agraria, Asociación Provincial de Agricultores y Ganaderos, Asociación General de Ganaderos del Reino, Federación de Trabajadores de la Tierra, Sindicato Remolachero, Unión Campesina de Valladolid y Unión de Ganaderos de Valladolid.

Este ilustrativo ejemplo cuestiona la tradicional imagen que ha tenido la opinión pública española sobre el campo, que comúnmente ha sido considerado un sector inmovilista, preso del individualismo, cuando no de la apatía política, de los agricultores ${ }^{2}$.

Sin embargo, como ya advirtieron diversos estudios sociológicos en las últimas décadas del pasado siglo, el agricultor español no fue un sujeto individualista, sino todo lo contrario, ya que participó en multitud de asociaciones de diverso tipo y condición: cámaras agrarias, juntas agropecuarias, cooperativas, comunidades de regantes, consejos reguladores de denominaciones de origen,

1 «Alrededor de quince mil agricultores y ganaderos se manifestaron contra la política agraria del Gobierno", El Norte de Castilla, 19-3-1980.

2 Por ejemplo, Jaime Lamo de Espinosa, ministro de Agricultura entre 1978 y 1981, quien ha dicho: «Los agricultores españoles son muy individualistas» (El Norte de Castilla, 23-9-2010). 


\section{IMAGEN I}

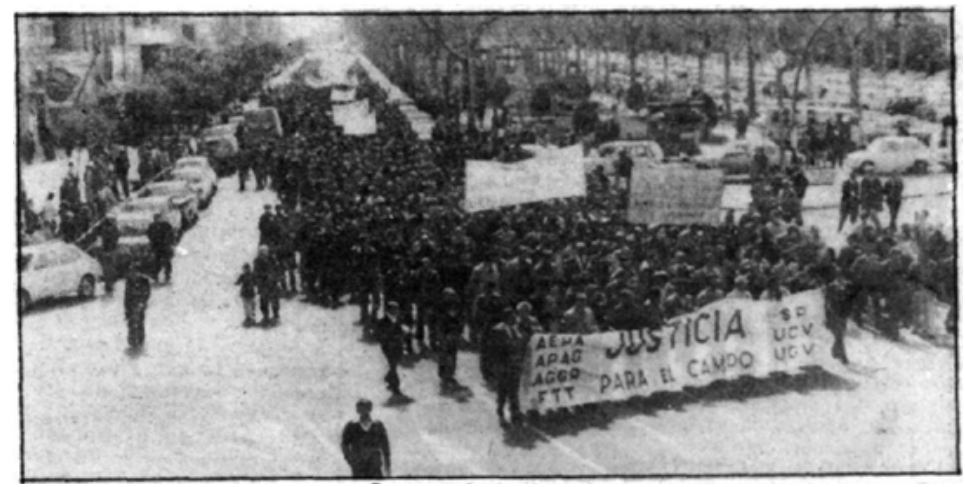

Fuente: El Norte de Castilla, 19-3-1980.

etc. ${ }^{3}$ De entre todas ellas, sin duda, las que han tenido mayor trascendencia política y social durante los últimos cuarenta años han sido los sindicatos agrarios u organizaciones profesionales agrarias (OPA), las cuales se han erigido en los representantes de los agricultores y ganaderos ante las distintas Administraciones ${ }^{4}$.

A pesar de esto, y a diferencia de los sociólogos, los historiadores sociales españoles marginaron durante demasiado tiempo al mundo rural, negando su protagonismo en el proceso de democratización y modernización socioeconómica de nuestro país ${ }^{5}$, hasta tal punto que todavía a las puertas del siglo XXI el campo seguía siendo, en palabras de S. Cruz Artacho (2001), el «hermano pobre» de la historia social española.

Afortunadamente, en los últimos quince años han proliferado numerosos estudios históricos que progresivamente han ido desmontando esa peyorativa imagen y han mostrado que la sociedad rural española también tuvo un papel activo en los distintos procesos políticos y sociales que ha vivido el país durante la contemporaneidad ${ }^{6}$, incluyendo el proceso democratizador que se produjo durante la Transición ${ }^{7}$. Un buen ejemplo de lo que acabamos de decir son los centenares de sindicatos agrarios que se crearon tras la muerte del

Moyano Estrada (1997): 774-775 y (2008): 17, y Gómez Benito (2001): 47-48.

Moyano Estrada (1984) y Fuente Blanco (1990).

González de Molina (2008): 98-99.

6 Por ejemplo, durante la Restauración: véase Herrera y Markoff (2013).

7 Un estado de la cuestión en Lanero y Míguez (2013). La última aportación a la larga nómina de trabajos sobre el tema: Quirosa-Cheyrouze y Martos (2019). 
dictador al margen del verticalismo ${ }^{8}$. Es decir, si la vida política y social del país durante aquellos años se caracterizó por la "sopa de letras»", no fue menos intensa la actividad asociativa que se produjo en el campo español, el cual vivió, parafraseando a una caricatura aparecida en un suplemento agrícola de El Norte de Castilla, su propia lluvia de siglas (imagen 2).

\section{IMAGEN 2}

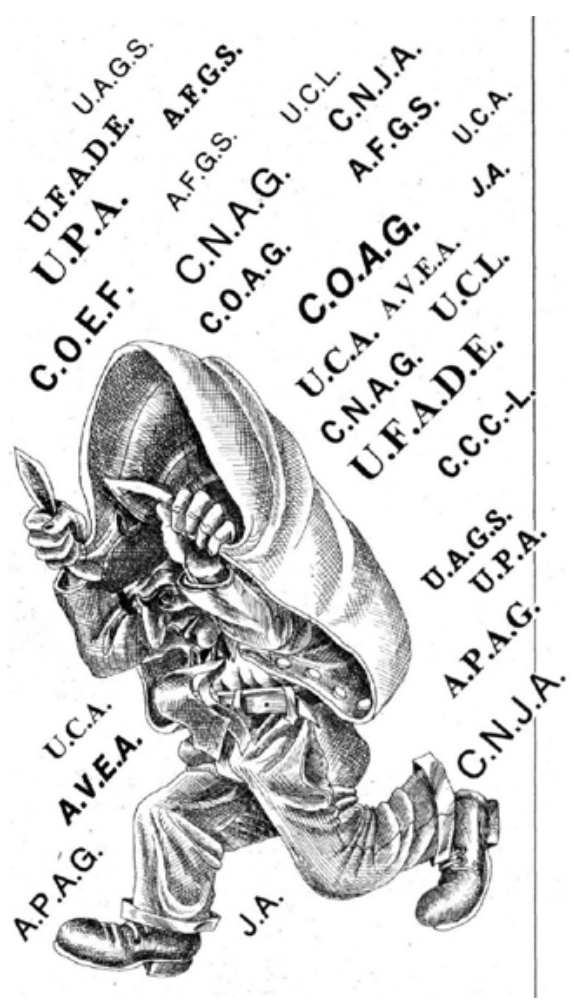

Fuente: El Norte del Campo, 26-2-1988

Con todo, y a pesar de los innegables avances, los estudios históricos sobre la Transición en la España rural en general, y el sindicalismo agrario en particular, todavía adolecen de algunas carencias ${ }^{10}$. Desde el punto de vista temático,

\footnotetext{
$8 \quad$ Moyano Estrada (1984): 170, y Herrera González de Molina (2007): 165.

Quirosa-Cheyrouze (2016).

10 Lanero y Míguez (2013): 21-26.
} 
por ejemplo, la mayoría de las investigaciones sobre sindicalismo agrario se han centrado en el estudio de asociaciones vinculadas a partidos de izquierda ${ }^{11} \mathrm{y}$, salvo algunas excepciones sobre el movimiento Jóvenes Agricultores ${ }^{12}$, han marginado el análisis de organizaciones agrarias de tendencia conservadora. Desde el punto de vista geográfico, por su parte, todavía faltan investigaciones que aclaren qué aconteció en importantes regiones rurales de España, como Castilla y León ${ }^{13}$, a pesar de que esta región fue, junto a Cataluña y Andalucía, uno de los principales focos del sindicalismo agrario durante la Transición ${ }^{14}$.

Teniendo en cuenta lo dicho, para seguir profundizando nuestro conocimiento sobre el papel que tuvo la sociedad rural española durante la Transición y cubrir parte de las carencias mencionadas, en este artículo realizaremos un estudio sobre la gestación, creación y primer desarrollo de los sindicatos agrarios, tanto conservadores como progresistas, que surgieron en la provincia de Valladolid durante la segunda mitad de los ańos setenta.

Por entonces, la agricultura vallisoletana se caracterizaba por el predominio de medianas (20-50 ha) y grandes (50-200 ha) explotaciones, la inmensa mayoría de ellas trabajadas directa y casi exclusivamente por mano de obra familiar. La producción agraria seguía dominada por cultivos herbáceos, especialmente cebada para forraje, que cada vez ocupaba más hectáreas en perjuicio del trigo. Las tierras de cereal se complementaban con algunas hectáreas dedicadas a cultivos de regadío, principalmente remolacha (pero también patata y alfalfa) y, en menor medida, vińedo, que por aquel entonces era un cultivo en retroceso. Lejos de ser un sector estancado, la agricultura vallisoletana de aquellos ańos estaba viviendo profundos cambios como consecuencia de la mecanización, la introducción de fertilizantes químicos y la implementación de regadíos y concentraciones parcelarias. La ganadería, por su parte, tenía un papel secundario, y dentro de ella destacaba el sector avícola, notablemente industrializado; el ovino, dominado por pequeños y medianos ganaderos, y ya mucho más marginal, el bovino de leche, que comúnmente servía de complemento en las explotaciones agrarias más pequeñas ${ }^{15}$.

Para realizar esta investigación hemos utilizado prensa provincial (El Norte de Castilla) y nacional (El País), documentación del fondo de Gobierno Civil del

11 Cabana Iglesia (2019): 153. Ejemplos de ello son: Sabio Alcutén (2001) y (2006); Herrera González de Molina (2007); Díaz Geada (2011); Díaz y Taboada (2014), y Fuentes y Cobo (2016).

12 Díaz Geada (2011): 111-115 y Ferrer Gálvez (2019).

13 Lanero y Míguez (2013): 21.

14 Fuente Blanco (1990): 28.

15 Gutiérrez Hurtado (1987). 
Archivo Histórico Provincial de Valladolid, y también, algunos testimonios orales recabados en primera persona ${ }^{16}$ o recogidos por terceros ${ }^{17}$. No obstante, antes de centrarnos en el caso vallisoletano, creemos necesario realizar un somero repaso del panorama sindical agrario español durante la Transición que permita una mejor contextualización y comprensión de nuestro caso de estudio.

\section{LA EVOLUCIÓN DEL PANORAMA SINDICAL DEL CAMPO ESPAÑOL DURANTE LOS AÑOS SETENTA}

La dictadura franquista creó una estructura sindical vertical en el campo a la que obligatoriamente debían pertenecer todos los agricultores del país. De este modo, los organismos de representación agraria se estructuraron en tres niveles territoriales (local, provincial y nacional) integrados, respectivamente, por las hermandades locales de labradores y ganaderos, las cámaras oficiales sindicales agrarias (COSA) y la Hermandad Nacional de Labradores y Ganaderos. La estructura del sindicalismo vertical agrario franquista se completó con los sindicatos nacionales de rama, que agrupaban todos los grupos laborales (empresarios, trabajadores, técnicos) de todos los sectores económicos (agrícola, industrial, comercial) que participaban en el proceso de producción de determinados productos agrícolas. De todos destacaron, por su poder e importancia, los sindicatos del Olivo y del Azúcar. Todos estos organismos tenían básicamente dos objetivos: uno económico, poner en práctica las políticas agrarias del Gobierno; y otro social, ser un instrumento del régimen franquista para controlar socialmente el campo ${ }^{18}$.

Con todo, en las últimas décadas del franquismo algunos grupos de agricultores comenzaron a cuestionar esta estructura corporativista por su incapacidad para defender los intereses de los profesionales del sector. Primero, ante los efectos de la crisis de la agricultura tradicional en los sesenta ${ }^{19}$. Después,

16 En concreto, hemos realizado entrevistas a: Juan Colino, diputado del PSOE por Valladolid entre 1977 y 1987 y portavoz de la comisión de agricultura del grupo socialista durante el período estudiado; Honorino Fernández, miembro fundador de Comisiones Campesinas de Valladolid y, posteriormente, primer coordinador de la Unión Campesina de Valladolid, y Félix Sacristán, también miembro de Comisiones Campesinas y, posteriormente, miembro fundador de Jóvenes Agricultores en Valladolid (hoy integrada en ASAJA).

17 González (1984) y Falces Yoldi (2006).

18 Ortiz Heras (1992) y Gil García (2005).

19 Moyano Estrada (1984): 141-142. 
ante las consecuencias de la política antiinflacionista de los Gobiernos de los setenta que, para contener la inflación en la cesta de la compra, limitaron la subida de los precios agrarios -mientras que, por el contrario, los precios de los insumos agrarios (combustible, fertilizante, maquinaria...) crecían según la tónica general-. La principal consecuencia de esta política fue la crisis de rentas del sector agropecuario, es decir, el descenso proporcional de las rentas de los agricultores y ganaderos respecto a las de los trabajadores del resto de sectores productivos ${ }^{20}$.

En este contexto, y del mismo modo que estaba ocurriendo en otros países de Europa como Francia y Portugal ${ }^{21}$, grupos de agricultores espańoles protagonizaron múltiples protestas ("guerras agrarias») que fueron organizadas al margen de los organismos verticales de representación agraria ${ }^{22}$. Estos grupos se habían conformado al amparo de activistas comunistas o sectores progresistas de la Iglesia católica y, posteriormente, terminaron creando las primeras uniones de Agricultores y Ganaderos (UAG), como fueron la Unió de Pagesos de Cataluña (creada en 1974) ${ }^{23}$, la Unión de Agricultores y Ganaderos de Aragón (creada en febrero de 1976 tras una "guerra del maíz»)24 o, en la cuenca del Duero, la Unión de Campesinos Zamoranos (UCZ), fundada en octubre de 1976 durante otra "guerra agraria» por la remolacha ${ }^{25}$. Estos grupos de agricultores buscaron organizarse a nivel nacional mediante la celebración de diversos encuentros de organizaciones campesinas, el primero de ellos celebrado el 1 de noviembre de 1975 en la localidad vallisoletana de Tudela de Duero, y los cuales culminaron con la creación, en diciembre de 1976, de la Coordinadora de Organizaciones de Agricultores y Ganaderos (COAG), entidad que agrupó a la mayor parte de las UAG existentes por aquel entonces ${ }^{26}$.

Pero no fue hasta después de la muerte de Franco cuando, del mismo modo que sucedió con la movilización social en el conjunto del país ${ }^{27}$, estalló la contestación de los agricultores, que no solo se tradujo en la multiplicación

\footnotetext{
20 Arnalte y Ceña (1993) y Abad y Naredo (1997). Un análisis de la «crisis de rentas» agropecuaria en la provincia de Valladolid, en Gutiérrez Hurtado (1987): 230-242.

21 Moyano Estrada (1988) y González Fernández (2019).

22 Alonso et al. (1976): 33.

23 Ferrer González (2018).

24 Sabio Alcutén (2001): 28-39.

25 «Presentación pública de «Unión de Campesinos Zamoranos»", El Norte de Castilla, 16-11-1976.

26 Moyano Estrada (1984): 197-203, y Sabio Alcutén (2006): 79-80.

27 Martín García (2010).
} 
de las protestas agrarias, entre las cuales destacó la «guerra de los tractores» de febrero-marzo de $1977^{28}$, sino también, como ya hemos apuntado, en la eclosión del asociacionismo agrario al margen del sindicalismo vertical.

En efecto, durante los primeros meses de la Transición se crearon más de trescientas asociaciones agrarias en toda España, muchas de las cuales se legalizaron tras la aprobación de la ley de Libertad Sindical de abril de 197729, surgiendo, ya de forma definitiva, las nuevas OPA. A partir de entonces, y durante la segunda mitad de 1977 y buena parte de 1978, se produjo un complejo proceso de federaciones, confederaciones, fusiones y absorciones que hizo que los varios centenares de OPA legalizadas al amparo del citado decreto se agruparan en cinco grandes centrales sindicales agrarias de ámbito nacional articuladas en torno a tres tendencias organizativas.

En primer lugar, surgió un sindicalismo agrario de clase compuesto esencialmente por pequeños y medianos agricultores que se agruparon en torno a dos organizaciones: la COAG, que como acabamos de ver surgió en diciembre de 1976 agrupando a la mayor parte de las UAG del país; y la Federación de Trabajadores de la Tierra de la Unión General de Trabajadores (FTT-UGT), que nació a raíz de los trabajos del sindicato socialista para refundar y reconstituir la vieja Federación Nacional de Trabajadores de la Tierra (FNTT) creada en los ańos treinta.

En segundo lugar, existió un sindicalismo agrario conservador de carácter empresarial que conformó la Confederación Nacional de Agricultores y Ganaderos (CNAG). Su origen está en la unión de las distintas asociaciones de Agricultores y Ganaderos (ASAGA) que se habían creado en numerosas provincias por iniciativa de las uniones de Empresarios vinculadas a las COSA. Su carácter netamente empresarial llevó a la CNAG a participar en la fundación de la Confederación Española de Organizaciones Empresariales (CEOE).

En tercer, y último lugar, también existió un sindicalismo agrario conservador de corte reformista, integrado por el Centro Nacional de Jóvenes Agricultores (CNJA) y la Unión de Federaciones Agrarias de España (UFADE). El origen del CNJA se remonta a inicios de los años setenta, cuando grupos reformistas vinculados a la Hermandad Nacional de Labradores y Ganaderos (Fernando Sanz Pastor) y al Opus Dei (Felipe González de Canales) impulsaron un movimiento de Jóvenes Agricultores siguiendo el modelo francés. Por su parte, UFADE sería el resultado de un segundo intento del propio CNJA, con apoyo de UCD, para federar a los distintos sindicatos agrarios

28 Moyano Estrada (1984): 206-208, y Langreo (1996): 61-63.

29 «Ley 19/1977 de 1 de abril, sobre regulación del derecho de asociación sindical», Boletin Oficial del Estado (BOE), 4-4-1977. 
conservadores cuyos asociados no se podían integrar en el CNJA por razones de edad y que, además, por razones sociales (eran pequeños y medianos agricultores) no se identificaban con el carácter empresarial de la CNAG. A pesar de su origen, UFADE no tardó en independizarse del CNJA, y ambas organizaciones iniciarán caminos distintos no exentos de enfrentamientos ${ }^{30}$.

En síntesis, fueron estas cinco asociaciones agrarias (COAG, FTT-UGT, CNJA, UFADE y CNAG) quienes representaron a la mayoría de los agricultores y ganaderos españoles ante las administraciones públicas durante la Transición y casi toda la década de los ochenta.

La importancia que alcanzaron estas OPA en la sociedad rural hizo que fueran foco de interés de los partidos políticos, los cuales buscaron atraerse el favor de los dirigentes y militantes de aquellas organizaciones ideológicamente más afines. De este modo, el PCE tuvo estrechas relaciones con amplios sectores de COAG; el PSOE tuvo influencia en otros sectores de COAG y, especialmente, en FTT-UGT; la UCD intentó vincularse con CNJA y UFADE; y, por último, $A P$ con $C N A G^{31}$.

Al margen la dimensión de las explotaciones y de la orientación ideológica de sus afiliados, estas tres tendencias organizativas se diferenciaron por sus demandas y las estrategias que preferentemente utilizaron para reivindicarlas. Respecto a las demandas, todas defendían la regulación de los precios agrarios para asegurar la rentabilidad de las explotaciones y, de ese modo, solventar la crisis de rentas de los trabajadores del sector. No obstante, la tendencia más empresarial centraba su discurso y acción casi exclusivamente en esta reivindicación, mientras que los reformistas también defendían que el Gobierno implementase políticas crediticias que permitieran la modernización de las pequeñas y medianas explotaciones agrarias, y, por su parte, los sindicatos de clase exigían la necesidad de combinar la regulación de precios agrarios con medidas complementarias que redujeran los costes de producción (control de precios de insumos, reducción de impuestos a pequeńas explotaciones) y fomentaran la construcción de infraestructuras e implementación de servicios sociales que mejorasen la calidad de vida en el mundo rural. Asimismo, los sindicatos de clase sumaron a las demandas de tipo económico una serie de reivindicaciones de carácter político y democrático, primero exigiendo la libertad sindical, y después solicitando el desmantelamiento de las cámaras agrarias, organismo que consideraban antidemocrático porque era sucesor de las viejas hermandades y socavaba la acción de los sindicatos libres ${ }^{32}$.

30 La génesis de las OPA españolas en Moyano Estrada (1984) y Fuente Blanco (1990). Específicamente sobre la FTT-UGT, véase Herrera González de Molina (2007).

31 Moyano Estrada (1984): 333-334, y Sabio Alcutén (2019): 231-234.

32 Moyano Estrada (1984): 174, 181 y 190. 
Por lo que se refiere a las estrategias que utilizaron para plantear sus demandas, en un primer período, hasta 1980, mientras los sindicatos conservadores privilegiaron la acción negociadora impulsando reuniones con diversos organismos de la Administración, los sindicatos de clase, y especialmente la COAG, combinaron esta acción negociadora con la movilización social, organizando campańas y acciones de protesta de muy diverso tipo (tractoradas, encierros, manifestaciones...). Estas estrategias cambiaron a partir de 1980 cuando, por un lado la COAG, en medio de una crisis interna, limitó el número y magnitud de sus movilizaciones de protesta, mientras que por otro los sindicatos conservadores comenzaron a utilizar la vía movilizadora ante la negativa del Gobierno a negociar los precios agrarios de aquel año, un cambio de estrategia que se consolidará con la llegada al poder del $\mathrm{PSOE}^{33}$.

\section{LOS SINDICATOS AGRARIOS CONSERVADORES EN LA PROVINCIA DE VALLADOLID: DEL VERTICALISMO AL SINDICALISMO LIBRE}

Durante el franquismo, el asociacionismo agrario vallisoletano estuvo articulado en torno a las hermandades de labradores y ganaderos -especialmente la COSA provincial- y el comúnmente conocido Sindicato Remolachero (SR). Con todo, estas no fueron organizaciones monolíticas, sino que integraron diversas tendencias ideológicas.

Por ejemplo, en la COSA vallisoletana existían claras diferencias entre dirigentes inmovilistas y sectores reformistas. Estos últimos se agruparon en 1974 con el objeto de impulsar una campaña para reclamar que los cargos de presidente y vicepresidente de la COSA provincial fueran «elegidos por sus representados, para después poderles exigir el cumplimiento de sus obligaciones y poderles felicitar cuando sus actuaciones fueran convincentes y censurarles cuando no fueren tanto ${ }^{34}$. Esta campaña fue liderada por Vicente Martín Calabaza, un agricultor de Olmedo notablemente conocido por sus asiduos artículos sobre agricultura publicados en El Norte de Castilla, en los cuales reivindicó reiteradamente la necesidad de desarrollar políticas que impulsaran «una reorganización total del campo español» y una «renovación total del Sindicalismo español» para mejorar la agricultura y la defensa de los intereses de los agricultores ${ }^{35}$.

33 Arribas y González (1984): 134-143, y Langreo (1996): 64-68.

34 «CORREO ESPONTÁNEO. Representatividad en el campo», El Norte de Castilla, 16-2-1975.

35 "La administración, el trigo y el pan», El Norte de Castilla, 30-3-1975; «Reivindicar», El Norte de Castilla, 8-6-1975. 
La pugna entre sectores inmovilistas y aperturistas fue patente en las elecciones sindicales de noviembre 1975 cuando, por primera vez, los presidentes de las COSA iban a ser elegidos por la Junta General de la Cámara, y no designados por el ministro de Agricultura ${ }^{36}$. En Valladolid se presentaron dos candidaturas: la inmovilista, encabezada por Francisco Bocos Cantalapiedra — presidente de la COSA y, posteriormente, primer delegado provincial de Fuerza $\mathrm{Nueva}^{37}$-, y la aperturista, liderada por Vicente Martín Calabaza. A pesar de todo, en diciembre de 1975, y ante «la falta de quorum durante las pasadas elecciones sindicales», el nuevo presidente de la COSA fue finalmente designado por el ministro de Relaciones Sindicales, quien nombró a Ciriaco Vázquez de Prada Costilla, miembro de un destacado linaje de empresarios agrarios ${ }^{38}$.

El SR, por su parte, se creó a finales de la década de 1910 con el nombre de Sindicato Agrícola de Cultivadores de Remolacha de Valladolid. Este sindicato es especialmente conocido porque fue la plataforma desde la que inició su actividad pública Onésimo Redondo, uno de los principales responsables de la primera refundación del SR bajo el nombre Sindicato de Cultivadores de Remolacha de Castilla la Vieja. El SR fue una de las pocas organizaciones sindicales que sobrevivió a la guerra civil, hecho propiciado, sin duda, por el destacado papel que tuvieron sus líderes en la victoria del bando franquista (entre ellos, el propio Onésimo Redondo) y por su proximidad ideológica con los postulados del nuevo régimen ${ }^{39}$.

A pesar de su historia, el SR mantuvo cierta independencia a la hora de defender los intereses de sus asociados frente a la industria azucarera y las políticas gubernamentales. Buen ejemplo de ello fue la creación de la Fábrica Azucarera Cooperativa Onésimo Redondo (ACOR), impulsada por dirigentes del SR para solventar los problemas de comercialización que tenían los remolacheros de la región con la industria azucarera, los cuales originaron varios conflictos en los años sesenta ${ }^{40}$.

Uno de los principales impulsores de ACOR fue Adolfo Sánchez García, presidente del SR desde 1961 y de la Agrupación Nacional Remolachera-Cañera-Azucarera desde 1963 y, por ostentar este cargo, también miembro de la

\footnotetext{
36 «Decreto 1016/1975, de 24 de abril, por el que se aprueba el Reglamento General de las Cámaras Oficiales Sindicales Agrarias», BOE, 13-5-1975.

37 Berzal de la Rosa (2001).

38 «El nuevo presidente de la COSA, don Ciriaco Vázquez de Prada, tomó posesión de su cargo", El Norte de Castilla, 9-12-1975.

39 Sobre la historia del SR: Baraja (1994): 133-141 y 228-235.

40 Alonso et al. (1976): 123-131, y Baraja (1994): 401-423.
} 
Confederación Internacional de Remolacheros Europeos ${ }^{41}$. Asimismo, fue elegido procurador en Cortes en 1967 como representante del tercio familiar, integrando el grupo de los «trashumantes», procuradores partidarios de implementar reformas que propiciaran la apertura política de la dictadura ${ }^{42}$. También fue delegado provincial de la Asociación Nacional para el Estudio de los Problemas Actuales (ANEPA), asociación política creada al amparo de la ley de asociaciones políticas de $1974^{43}$, que abogaba por un régimen político basado en una "constitución», la «libertad» y la "cooperación al bien común»"

Durante los primeros meses de la Transición, el propio Adolfo Sánchez García defendió públicamente la necesidad de realizar políticas que impulsaran, entre otros aspectos, la libre asociación de los agricultores: «Lo que sí desearíamos es, la coincidencia de los hombres por sus intereses, en agrupaciones, uniones o sindicatos, sea cual fuere su ideología política, pues creo que del polimorfismo de ideas dentro de la "unidad" (profesional, sectorial, o la que fuere), pueden salir las soluciones reales y auténticas de nuestros problemas agrarios» ${ }^{45}$.

No obstante, los problemas de la agricultura eran tan profundos que incluso las élites agrarias más afines a la dictadura criticaron abiertamente las políticas agrarias gubernamentales durante las décadas de 1960 y $1970^{46}$. Por ejemplo, Rafael del Águila Goicoechea, un destacado empresario ganadero y uno de los procuradores que votó en contra de la Ley para la Reforma Política en noviembre de $1976^{47}$, clamaba en Cortes el mes de julio anterior: «¿Cuándo va la Administración a tomar en serio el cálculo de los costes de producción agrarios?» ${ }^{48}$. Por ello no es de extrañar que los propios organismos verticales de representación agraria patrocinaran algunas protestas públicas, entre las que destacó la asamblea extraordinaria organizada el 3 de julio de 1976 en Madrid por la Hermandad Nacional de Labradores y Ganaderos para protestar por la política de precios del Gobierno, donde se reunieron 10000 representantes de hermandades de toda España ${ }^{49}$.

41 Orrasco García (2010): 21.

42 Miranda Rubio (1994).

43 «Decreto-Ley 7/1974, de 21 de diciembre por el que se aprueba el Estatuto Jurídico del Derecho de Asociación Política», BOE, 23-12-1974.

44 Archivo Histórico Provincial de Valladolid (AHPV), Gobierno Civil, Caja 1460, Carp. 3, 23-11-1975.

45 "Atención del campo y a sus problemas», El Norte de Castilla, 9-7-1976.

46 González Fernández (2015): 106.

47 Gallego (1987): 481.

48 «Los costes no son fundamentales para los precios agrarios», El Pais, 17-7-1976.

49 «Críticas enérgicas a la política agraria de la Administración», El País, 4-7-1976. 
Por aquellos días, algunas COSA castellanas también organizaron manifestaciones de protesta, como ocurrió en Palencia ${ }^{50}$ o Valladolid, donde la manifestación fue encabezada por «los Presidentes de la Diputación Provincial, de la Cámara Oficial Sindical Agraria y Cámara de la Propiedad Urbana, los Consejeros Nacionales D. Anselmo de la Iglesia Somavilla y D. Dionisio Martín Sanz, Procurador en Cortes D. Adolfo Sánchez [García] y el presidente de la Unión de Empresarios [Mariano Vázquez de Prada]" y secundada por miles de manifestantes que portaron pancartas «en las que se pedía precios justos, justicia para el campo, seguridad social para sus trabajadores y otras de similar significado ${ }^{51}$.

En este contexto surgieron las primeras asociaciones agrarias al margen del verticalismo, como la Asociación Regionalista Agraria (ARA) ${ }^{52}$, liderada por Alberto Ballarín Marcial, profesor de Derecho Agrario que posteriormente fue diputado de UCD entre 1977 y $1982^{53}$. Aunque sus impulsores reconocían «la labor que las Cámaras Agrícolas españolas han hecho por la defensa de la agricultura española», no obviaban que "como Organismo Oficial, siempre ha estado coartada por la más poderosa Voz Ministerial», por lo que defendían un modelo de representatividad agraria similar al existente en otros países de Europa occidental, donde "hay organizaciones profesionales agrarias que defienden a los empresarios y que cuentan en los parlamentos con representantes elegidos en la base que llevan la voz de cada región y sus propios problemas agrícolas ${ }^{54}$.

Ese mismo año también se creó en Valladolid una Asociación Libre de Jóvenes Agricultores que pretendía aglutinar «a todos aquellos jóvenes de uno y otro sexo que trabajando en la agricultura, ganadería o labores domésticas en los pueblos, sientan inquietudes y estén dispuestos a contribuir al logro de unas comunidades rurales más abiertas, aumentando su nivel cultural y promocionando la participación de la Juventud en la ordenación de la vida comunitaria $"$ " 5 . A pesar de que esta asociación apenas tuvo recorrido, era un esclarecedor síntoma de que algo se estaba moviendo en el campo vallisoletano más allá de la COSA.

50 "Unos quince mil labradores participaron en la manifestación pacífica», El Norte de Castilla, 1-7-1976.

51 «Impresionante manifestación del campo vallisoletano», El Norte de Castilla, 31-71976. Las cursivas son nuestras.

52 «ARA y la mejora del medio rural», El Norte de Castilla, 8-6-1976.

53 Breve nota biográfica sobre Alberto Ballarín Marcial en: https://bit.ly/32GW2nG (consultada el 28-10-2019).

54 «Necesidad de una Asociación Regionalista Agraria», El Norte de Castilla, 6-6-1976.

55 «Hacia la constitución de una Asociación Libre de Jóvenes Agricultores», El Norte de Castilla, 23-3-1976. 
Con todo, no fue hasta febrero-marzo de 1977 cuando, como ya referimos, se produjo la mayor protesta agraria de la Transición, la "guerra de los tractores», y con ella, la crisis definitiva del sindicalismo vertical en el campo español ${ }^{56}$. En efecto, una de las principales motivaciones que llevaron a los agricultores del país a tomar las carreteras con sus tractores era su frustración ante «unos órganos [verticales] que a la hora de plasmar las necesidades del campo no han demostrado la suficiente representatividad e identificación con las auténticas reivindicaciones del sector $\aleph^{57}$. Ante esta situación, grupos de grandes agricultores vinculados a la Unión Nacional de Empresarios Agrícolas conformaron diferentes ASAGA provinciales al margen de las COSA, con el objetivo de aprovechar el descontento existente para reubicarse en el nuevo panorama sindical agrario que se avecinaba y, de este modo, mantener su influencia en el campo español ${ }^{58}$.

Los primeros ecos de la "guerra de los tractores» llegaron a Valladolid con la circulación de una hoja volandera que apareció en los últimos días del mes de febrero con el título «Operación Reivindicaciones Agrarias Valladolid $~^{59}$, que reivindicaba mejores precios para los cereales, patata y remolacha, igualdad en el régimen agrario de la seguridad social y la implementación de infraestructuras agrarias (regadío, concentración parcelaria). Este documento fue asumido de forma inmediata por una nueva organización agraria, la Asociación Provincial de Agricultores y Ganaderos (APAG) ${ }^{60}$, creada en una reunión celebrada los días 25 y 26 de febrero por algunos dirigentes de la COSA liderados por Mariano Vázquez de Prada, que era presidente de la Unión de Empresarios de la COSA (y hermano del presidente de la propia Cámara Sindical), el cual, incluso, fue detenido por la guardia civil durante la tractorada ${ }^{61}$. Esta nueva asociación se autodefinió como "profesional, libre, apolítica, independiente y democrática» ${ }^{62}$.

Pocos días más tarde, el 1 de marzo, apareció en escena la Asociación Empresarial Provincial Agraria (AEPA), liderada por Vicente Martín

56 Moyano Estrada (1984): 206-208, y Langreo (1996): 61-63.

57 "Manifestaciones campesinas: algo más que la patata», El País, 26-2-1977.

58 Moyano Estrada (1984): 230-231, y Fuente Blanco (1990): 264.

59 AHPV, Gobierno Civil, Caja 1048, Carp. 17, 28-2-1977.

60 AHPV, Gobierno Civil, Caja 1048, Carp. 19, 28-2-1977.

61 De hecho, en las protestas fueron detenidos: «Ciriaco Vázquez de Prada, presidente de la COSA de Valladolid; Pedro Vázquez de Prada, presidente de la Caja Rural; y Mariano Vázquez de Prada, presidente de la Unión de Empresarios», en «Las carreteras de Valladolid, desbloqueadas", El Norte de Castilla, 2-3-1977.

62 "Valladolid: seis mil tractores en las carreteras», El Norte de Castilla, 1-3-1977; «Las carreteras de Valladolid, desbloqueadas», El Norte de Castilla, 2-3-1977. 
Calabaza y Adolfo Sánchez Martín (hijo de Adolfo Sánchez García) como presidente y secretario, respectivamente, y con claro apoyo desde El Norte de Castilla $^{63}$. El manifiesto fundacional de AEPA señalaba que ante el hecho «indudable [de] que la Organización Sindical Verticalista se desmorona» y de que «los dirigentes de la Hermandad quieren jugar una alternativa [APAG] para seguir con su posición de privilegio en el sindicalismo agrario», proponían la creación de "una asociación independiente de empresarios agrarios» que se autocalificaba como «libre, democrática, participativa, reivindicativa, dialogante, unitaria, formativa, informativa y comunitaria» ${ }^{64}$.

El panorama del sindicalismo agrario conservador vallisoletano lo completó la sección provincial de la Asociación General de Ganaderos del Reino (AGGR), creada a mediados del mes de febrero. Esta asociación se creó primigeniamente en 1836 sucediendo a la Mesta, y durante la dictadura franquista se integró en el vertical Sindicato Nacional de Ganadería. La nueva AGGR surgió ante la idea de que «la libertad de asociación será establecida», lo que podría provocar una "proliferación de asociaciones [...] ocasionando una disgregación de la clase ganadera». En este sentido, para agrupar a los ganaderos de todo tipo, la asociación se consideró "estrictamente profesional, independiente y apolítica» y estableció que sus cargos directivos «se proveerán mediante elecciones libres y democráticas, sin que exista propósito alguno de continuismo por parte de los actuales dirigentes de la Agrupación general de ganaderos» ${ }^{65}$.

El estallido de la "guerra de los tractores» y la creación de todas estas nuevas asociaciones agrarias produjeron una profunda crisis tanto en la COSA como en la Hermandad de Labradores de Valladolid, donde "por primera vez en una asamblea abierta a medias, los propios presidentes de la Hermandad oyeron palabras que hacían dudar de la validez de las mismas [...]. Todo ello ha hecho que el mundo agrario se empiece a plantear la validez o no de los

63 Que insertó recurrentemente en sus páginas artículos de opinión de sus líderes, información detallada de sus actividades sindicales y anuncios que promovían la afiliación en AEPA.

64 «Se crea la Asociación Empresarial Provincial Agraria de Valladolid», El Norte de Castilla, 1-3-1977 y «Don Adolfo Sánchez habló en el INEA sobre una nueva Asociación Sindical Agraria», El Norte de Castilla, 11-3-1977. Sobre la conformación de AEPA véase la entrevista al propio Adolfo Sánchez Martín en González (1984): 201-205.

65 "Gestiones para crear una Asociación General de Ganaderos», El Norte de Castilla, 17-2-1977. 
sistemas actuales». Como resultado de esta crisis dimitieron, entre otros, el propio presidente de la COSA, Ciriaco Vázquez de Prada ${ }^{66}$.

La puntilla al sindicalismo vertical agrario se produjo con la promulgación de la ley de libertad sindical de abril de 1977, y pocas semanas más tarde del real decreto ley de junio de 1977 que ponía fin a la sindicación obligatoria $^{67}$. Con estas leyes, las distintas asociaciones agrarias que habían surgido hasta entonces no tardaron en legalizarse y constituirse en OPA.

En efecto, AEPA se legalizó a inicios de junio, con una estructura organizativa inspirada en "otras organizaciones similares europeas» y con unos estatutos donde tenían cabida "todas las ideologías, a excepción del marxismo» porque «no podemos consentir por ningún concepto que se pueda atentar contra la propiedad privada». La misma asamblea constituyente ratificó en sus cargos a Vicente Martín Calabaza como presidente, y a Adolfo Sánchez Martín como secretario de la nueva asociación ${ }^{68}$.

Pocas semanas más tarde, a inicios de julio, se legalizó APAG, con el objeto de «dedicar una especialísima atención a la mejora de nuestros pueblos, servicios sanitarios, vivienda, enseñanza, deporte y todo lo que redunde en beneficio de los hombres que hoy viven en el campo». La propia asamblea constitutiva ratificó como presidente a Mariano Vázquez de Prada, quien manifestó que la principal reivindicación de la asociación sería pedir «unos precios agrarios que terminaran con la injusta discriminación del sector ${ }^{69}$.

En los mismos días se constituyó la Junta Provincial de la AGGR, como una asociación "totalmente apolítica y exclusivamente profesional», donde tenían cabida «todos los ganaderos de la provincia, ya sea a grande o pequeńa escala [...] para crear un frente común para así defender mejor los intereses profesionales de la ganadería vallisoletana $»^{70}$.

Por último, en el propio mes de julio, los cultivadores remolacheros, con Adolfo Sánchez García a la cabeza, aprovecharon la legislación vigente para

66 «Dimisiones de la Cámara Sindical Agraria», El Norte de Castilla, 11-3-1977.

67 «Real Decreto-ley 31/1977, de 2 de junio, sobre extinción de la sindicación obligatoria, reforma de estructuras sindicales y reconversión del Organismo autónomo "Administración Institucional de Servicios Socio-Profesionales»", BOE, 8-6-1977.

68 «Constituida la Asociación Empresarial Agraria (AEPA)», El Norte de Castilla, 24-61977.

69 "Asamblea de Trabajadores Autónomos de Agricultura», El Norte de Castilla, 10-71977 y «Es urgente la actualización de los precios en los productos agrarios», El Norte de Castilla, 13-7-1977.

70 "Constituida la Junta Provincial de la Asociación General de Ganaderos del Reino», El Norte de Castilla, 9-7-1977. 
reconstituir el $\mathrm{SR}^{71}$. Ambas asociaciones, AGGR y $\mathrm{SR}$, mantendrán una estrecha relación con AEPA, basadas en el papel preponderante que tuvieron en estas tres asociaciones Adolfo Sánchez García y su hijo Adolfo Sánchez Martín. En efecto, Adolfo Sánchez Martín (hijo) fue secretario de AEPA y también presidente de la Sección Avícola Provincial de la AGGR ${ }^{72}$. Por su parte, Adolfo Sánchez García (padre) fue presidente y alma del SR y también fue nombrado presidente de honor de $\mathrm{AEPA}^{73}$. Asimismo, ambos darán el salto a la política de la mano de UCD: el padre fue diputado por Valladolid durante la legislatura constituyente, y el hijo concejal en el ayuntamiento de Valladolid tras las elecciones de $1979^{74}$.

La constitución de todas estas nuevas OPA conservadoras vallisoletanas dio paso a un doble proceso organizativo. En primer lugar, el desarrollo de una intensa actividad sindical basada en la celebración de multitud de reuniones, asambleas y mítines en distintos pueblos de la provincia. Así, por ejemplo, según el propio Adolfo Sánchez Martín, AEPA celebró más de ciento cincuenta reuniones en la provincia a lo largo de 1977 defendiendo la organización sindical libre y democrática ${ }^{75}$. En segundo lugar, y del mismo modo que sucedió en el resto del país ${ }^{76}$, estos nuevos sindicatos agrarios vivieron un proceso de reorganización mediante tres vías: fusiones (o intentos de fusiones), coaliciones (de cara las elecciones a cámaras agrarias) y federaciones (a nivel regional y nacional).

Un primer paso a la convergencia de los sindicatos agrarios conservadores vallisoletanos fue el primer intento de fusión de las dos OPA conservadoras más importantes de la provincia: APAG, apoyada en la estructura de la antigua COSA; y AEPA, con apoyo de sectores agrarios reformistas que se extendían desde el SR hasta el El Norte de Castilla ${ }^{77}$. No obstante, las negociaciones fracasaron, iniciándose una etapa en la que ambas asociaciones mantuvieron unas relaciones competitivas marcadas por la lucha por atraer a sus filas a agricultores de un mismo sector ideológico ${ }^{78}$.

71 El Norte de Castilla, 16-7-1977, y AHPV, Gobierno Civil, Caja 572, Carp. 1, Exp. 11, 31-7-1977.

72 AHPV, Gobierno Civil, Caja 762, Carp. 1, Exp. 10, 31-10-1978.

73 "Don Adolfo Sánchez García, presidente de honor de AEPA», El Norte de Castilla, 30-3-1979.

74 Berzal de la Rosa (2001).

75 González (1984): 202.

76 Moyano Estrada (1984): 170.

77 «Reunión de Asociaciones Profesionales Agrarias en San Rafael», El Norte de Castilla, 22-10-1977.

78 Un resumen sobre las relaciones entre APAG y AEPA en Fuente Blanco (1990): 285-288. 
Fracasada la fusión, se produjo un nuevo intento de convergencia mediante la creación de una organización federal de carácter regional, la Federación Regional de Agricultores y Ganaderos de la Cuenca del Duero, que se constituyó en diciembre de 1977 con la participación de AEPA y APAG y otros sindicatos agrarios similares de Ávila, Burgos, Palencia, Segovia, Salamanca, Soria y Zamora, la cual fue presidida por el presidente de APAG, Mariano Vázquez de Prada ${ }^{79}$. Este segundo intento de aproximación entre APAG y AEPA tampoco fructificó, ya que esta última asociación terminó abandonando la Federación de la Cuenca del Duero porque el resto de asociaciones de la federación no aceptaron la integración en la misma de la AGGR y del SR, organizaciones que tenían una estrecha relación con AEPA ${ }^{80}$.

Por aquellos días, AEPA ya había iniciado otro proceso de confederación junto otras asociaciones agrarias de ámbito nacional para conformar la $\mathrm{CNAG}^{81}$, proceso en el cual tuvo un papel destacado Adolfo Sánchez Martín, secretario de AEPA, quien fue elegido presidente de la nueva OPA nacional ${ }^{82}$. Este hecho hizo que APAG no entrara (por el momento) en la CNAG, a pesar de que este debía ser su destino natural, puesto que la CNAG fue la central sindical que aglutinó a la mayor parte de las ASAGA que, como la propia APAG, se crearon al amparo de las distintas Uniones de Empresarios de las COSA del país ${ }^{83}$. Por el contrario, APAG sí fue una de las asociaciones fundadoras de la Federación Independiente de Sindicatos Agrarios (FISA) en abril de 1978, el primer intento del CNJA para conformar una federación nacional de sindicatos agrarios conservadores de corte reformista, organización que se desintegró al poco de nacer ${ }^{84}$.

De cara a las elecciones a cámaras agrarias del 21 de mayo de $1978^{85}$, tanto AEPA como APAG buscaron conformar sendas coaliciones electorales junto al resto de asociaciones agrarias conservadoras de la provincia. AEPA se coaligó

79 «Mariano Vázquez de Prada, presidente de la Federación Regional de Agricultores y Ganaderos», El Norte de Castilla, 9-12-1977.

80 "AEPA se retira de la Federación de Agricultores y Ganaderos de la Cuenca del Duero», El Norte de Castilla, 21-2-1978; "Comunicado de la Federación Regional de Agricultores y Ganaderos de la Cuenca del Duero", El Norte de Castilla, 4-3-1978; "Aclaraciones de la Asociación Provincial de Agricultores y Ganaderos (APAG)», El Norte de Castilla, 9-3-1978.

81 Fuente Blanco (1990): 285-286.

82 «Adolfo Sánchez Martín, de Valladolid, presidente de la Confederación Nacional de Labradores y Ganaderos», El Norte de Castilla, 13-12-1977.

83 Moyano Estrada (1984): 230-231 y Fuente Blanco (1990): 264.

84 Ibid.: 247-248.

85 Ibid.: 270-279 y Herrera González de Molina (2007): 98-102. 
con el SR y la AGGR para conformar la Coalición Electoral a Cámaras Agrarias $^{86}$, certificando las estrechas relaciones que tenían estas tres asociaciones.

APAG, por su parte, se coaligó con la sección vallisoletana de ARA y con el incipiente grupo de Jóvenes Agricultores ${ }^{87}$. Esta última organización se había conformado el propio año $1978^{88}$, aunque según la documentación manejada tuvo una presencia residual en el panorama sindical agrario de la provincia hasta después de 1980. El éxito electoral de la coalición liderada por APAG permitió que, poco más tarde, esta asociación se fusionara (o más bien absorbiera) a ARA, ya que ambas asociaciones tenían una «idea de sindicalismo agrario apolítico [que] coincide plenamente» ${ }^{89}$.

Este complejo proceso de reorganización del panorama sindical de la provincia se completó en octubre de 1978 cuando APAG, junto al resto de asociaciones que integraban la Federación de la Cuenca del Duero y otras asociaciones agrarias españolas, conformaron UFADE, el segundo intento del CNJA, esta vez exitoso, para crear una asociación agraria nacional alternativa a la CNAG que aglutinara a sindicatos agrarios conservadores de tendencia reformista ${ }^{90}$.

La pugna entre APAG y AEPA se mantuvo hasta 1986, cuando esta última asociación se disolvió tras una ruinosa operación económica que pretendió comercializar de forma conjunta la cebada de sus asociados ${ }^{91}$. La disolución de AEPA dejó la vía libre para que APAG retomase su cauce natural dentro del panorama sindical agrario nacional y se integrase en la CNAG junto al resto de ASAGA del país ${ }^{92}$.

86 "Acuerdo entre AEPA, Sindicato Remolachero y Asociación General de Ganaderos del Reino", El Norte de Castilla, 4-4-1978.

87 «APAG, ARA, y Jóvenes Agricultores participarán unidas en las elecciones a Cámaras Agrarias», El Norte de Castilla, 9-4-1978.

88 Entrevista a Félix Sacristán. Cogeces del Monte (Valladolid), 3-7-2019.

89 "La fusión de APAG y ARA está sólo pendiente de la formalización del trámite», $E l$ Norte de Castilla, 26-5-1978; «La fusión de APAG y ARA, aprobada», El Norte de Castilla, 4-7-1978;

90 "Constituida la Unión de Federaciones Agrarias de España», El Norte de Castilla, 28-10-1978.

$91 \quad$ Falces Yoldi (2006): 187-191.

92 Fuente Blanco (1990): 288. 


\section{LOS SINDICATOS AGRARIOS DE CLASE EN LA PROVINCIA DE VALLADOLID: DE LA CLANDESTINIDAD A LA LEGALIDAD}

El sindicalismo agrario de clase (o progresista) durante la Transición tuvo su origen en la clandestinidad durante el tardofranquismo, principalmente como consecuencia de la acción organizativa de activistas vinculados a distintos partidos comunistas (PCE, PTE, ORT...) - que impulsaron la conformación de Comisiones Campesinas (CC.CC.) en diversas partes del país- y a sectores progresistas de la Iglesia (como Acción Católica y, más específicamente, la Juventud de Acción Rural Católica -JARC-) ${ }^{93}$. En este sentido, la provincia de Valladolid no fue una excepción.

En efecto, ya durante en 1969 tenemos noticia de la existencia de unas CC.CC. de Valladolid porque delegados de las mismas asistieron a la IV Reunión General de las Comisiones Obreras celebradas en abril de aquel ańo ${ }^{94}$. No obstante, todo parece indicar que esta primigenia organización provincial de agricultores contestatarios apenas tuvo recorrido, puesto que no tenemos noticias de que representantes de la misma volvieran a asistir a reuniones o asambleas similares, como fue la Asamblea General de Comisiones Obreras Agrícolas y Campesinas del Estado Español, celebrada en mayo de $1970^{95}$. No obstante, la desaparición de estas primeras CC.CC. de Valladolid no impidió que durante los primeros años setenta siguieran apareciendo por diversos pueblos de la provincia algunos folletos y pasquines de propaganda comunista que trataban diferentes problemas agrarios y que insistían en la necesidad de organizar unas CC. CC. ${ }^{96}$ Este deseo finalmente se materializó en mayo de 1976, cuando se constituyeron unas nuevas CC. CC.

93 Moyano Estrada (1984): 197-198; Bernal (2001): 38-39, y Sabio Alcutén (2019): 21-23.

94 Según Ariza (1976: 124), a esta reunión asistieron «delegados de las Comisiones Obreras Agrícolas y las Comisiones Campesinas de Aragón, Cádiz, Lérida, Sevilla, Toledo y Valladolid».

95 A donde, según Fuentes y Cobo (2016: 187), asistieron delegados de Andalucía, Cataluña, Aragón, Toledo, Albacete, Ciudad Real, Valencia, Logrońo y Galicia.

96 «Carta abierta a los hombres del campo. Redactada por un grupo de campesinos afectados», AHPV, Gobierno Civil, Caja 1031, Exp. 83, 7-1968; «La remolacha ¿es un cultivo problema?», AHPV, Gobierno Civil, Caja 1029, Carp. 6, 7-1972; «Contra las importaciones. Hacia la democracia», AHPV, Gobierno Civil, Caja 1029, Exp. 41, 10-1974; "Crisis en el campo castellano», AHPV, Gobierno Civil, Caja 1029, Exp. 41, 17-12-1974. 
que, según su manifiesto fundacional, se conformaban como un sindicato "horizontal, independiente, único [...] [y] democrático»"

La creación de esta nueva organización fue fruto de la actividad propagandista que llevó a cabo Fernando Moráis de la Horra, un joven médico perteneciente al PTE que había desarrollado parte de su actividad sanitaria en el medio rural vallisoletano. La presencia de las CC. CC. de Valladolid se consolidó en las comarcas orientales de la provincia (Campo de Peñafiel y Valle del Esgueva), donde algunos grupos de agricultores realizaron una intensa campańa de propaganda mediante la celebración clandestina de reuniones de agricultores en almacenes, pinares o casas particulares, en las cuales se planteaban y discutían los problemas que tenía la agricultura provincial y la forma de organizarse al margen del sindicalismo vertical ${ }^{98}$.

La primera aparición pública de estas nuevas CC. CC. se produjo en junio de 1976, cuando organizaron una asamblea general a la que asistieron unos ciento veinte agricultores y donde se presentaron las primeras reivindicaciones de la organización, relacionadas con los problemas originados por la sequía ${ }^{99}$. Pocas semanas más tarde, las CC.CC. protagonizaron su primera acción pública de protesta cuando un grupo formando por alrededor de mil agricultores de la organización provenientes de Valladolid y Segovia participaron en la manifestación que organizó la COSA vallisoletana el día 30 de julio, portando pancartas en las que, además de demandas propiamente sectoriales (mejora de precios), también reivindicaban la libertad sindical, lo que dio origen a algunos incidentes entre diferentes grupos de manifestantes ${ }^{100}$.

La culminación de la actividad de las CC.CC. en la región castellana y leonesa se produjo pocos meses más tarde, en octubre de 1976, cuando varios representantes de las mismas se reunieron en Valladolid para acordar la creación de las CC.CC. de Castilla y León con el objetivo de avanzar «hacia la formación de nuestro propio Sindicato Campesino regido por nosotros y para resolver

97 «Constituidas desde mayo las Comisiones Campesinas de Valladolid», El Norte de Castilla, 20-6-1976.

98 Entrevista a Honorino Fernández. Peńafiel (Valladolid), 22-7-2019.

99 «Constituidas desde mayo las Comisiones Campesinas de Valladolid», El Norte de Castilla, 20-6-1976.

100 "Impresionante manifestación del campo vallisoletano", El Norte de Castilla, 3-7-1976. Uno de los implicados en estos incidentes fue Félix Sacristán, entrevistado en Cogeces del Monte (Valladolid), 3-7-2019. 
nuestros problemas» frente a «los altos dirigentes del aparato sindical [que] están tratando de lavar la fachada de las Hermandades y Cámaras Oficiales» ${ }^{101}$.

Más conocida es la acción democratizadora que tuvieron los sectores progresistas de la Iglesia católica en la provincia de Valladolid ${ }^{102}$. La principal expresión de esta acción en los ámbitos rurales provinciales fue la creación, por impulso de Acción Católica (y concretamente de María Luisa Jolín, presidenta del Movimiento Rural Diocesano), de los Colegios Familiares Rurales, a través de los cuales se pretendía dotar de una formación profesional agraria a los jóvenes del medio rural. De este modo, a finales de los sesenta se crearon colegios familiares rurales en Tudela de Duero, Medina de Rioseco, Mayorga, Mojados y Tordesillas. El proyecto culminó en 1969 con la fundación del Instituto Rural El Pino en Valladolid, que ofrecía estudios de bachillerato a los jóvenes de familias de agricultores. Algunos de estos centros educativos (especialmente el colegio de Tudela y el Instituto El Pino) fueron foco para la promoción de valores democráticos en el mundo rural vallisoletano mediante la acción de algunos profesores vinculados a grupos políticos y sindicales de la oposición lo cual, a la postre, fue un factor clave para impulsar el sindicalismo agrario progresista a nivel provincia ${ }^{103}$, regional ${ }^{104}$, e incluso nacional, puesto que, como ya hemos apuntado, fue precisamente en el Colegio Familiar Rural de Tudela de Duero donde, al amparo de la JARC, se organizó y celebró el I Encuentro de Organizaciones Campesinas, al que acudieron alrededor de cuarenta representantes de diversos grupos de agricultores contestatarios procedentes de diversas partes de España, muchos de ellos vinculados a partidos como el PCE, PTE u ORT ${ }^{105}$.

En este contexto, a finales de 1975, un grupo de agricultores vallisoletanos reunidos en el Instituto Rural El Pino fundaron el Movimiento Campesino de Base (MCB). En este grupo coexistían dos claras tendencias: una más relacionada con Acción Católica y otra vinculada al $\mathrm{PCE}^{106}$. La primera se conformó en torno a las asociaciones de padres de los colegios familiares rurales, y estaba encabezada, entre otros, por José Antonio Arias. La segunda estaba liderada por Maximiano (Maxi) Rodríguez, un personaje determinante en el surgimiento y evolución del sindicalismo agrario de clase en Valla-

101 «El domingo quedaron constituidas las Comisiones Campesinas de Castilla y León», El Norte de Castilla, 5-10-1976, y "Comisiones Campesinas, a favor de precios de garantía para el agro", El Pais, 6-10-1976.

102 Serrano Blanco (2006) y Berzal de la Rosa (2007) y (2018).

103 Serrano Blanco (2006): 263-268.

104 Por ejemplo, en la provincia de León: Martínez Pérez (2015): 291.

105 Moyano Estrada (1984): 197-200, y Sabio Alcutén (2019): 224.

106 Entrevista a Rafael Martín y José Antonio Arias, en Falces Yoldi (2006): 62-65. 
dolid, y cuyo prestigio traspasó las fronteras provinciales, como muestra el hecho de que fuera quien prologó el famoso «libro negro» de las luchas agrarias publicado en $1976^{107}$.

Maxi Rodríguez nació en Castromonte (Valladolid), en el seno una familia jornalera que durante la II República se vinculó a partidos y sindicados de izquierda, por lo que diversos miembros de la familia sufrieron la represión (su hermano fue paseado y su padre encarcelado). Con los años logró adquirir unas tierras y convertirse en agricultor por cuenta propia, pero no abandonó las ideas políticas de su familia y durante el tardofranquismo se vinculó al PCE, siendo miembro del comité provincial en la clandestinidad ${ }^{108}$.

Durante la primera mitad del ańo 1976, el MCB tuvo una notable actividad y celebró numerosas reuniones clandestinas en los propios colegios familiares rurales y algunas iglesias, donde trataban los problemas de la agricultura y la forma de consolidar la organización a nivel provincial ${ }^{109}$. Por ejemplo, sabemos de la celebración de reuniones periódicas en un bar de Medina de Rioseco, a las que asistieron agricultores de numerosos pueblos de las comarcas occidentales de la provincia (Tierra de Campos y Montes Torozos), en donde se trataban y discutían problemas agrícolas (precios) y organizativos ${ }^{110}$.

En estas reuniones se gestó la primera acción pública del MCB, el conocido «Manifiesto de la cebada», publicado parcialmente por El Norte de Castilla. Este documento, firmado por 2400 agricultores de la provincia y cuyos promotores fueron calificados de «subversivos» por la COSA, solicitaba que el Servicio Nacional de Productos Agrarios (SENPA) comprara los grandes excedentes de cebada que existían en la provincia ${ }^{111}$.

Tanto las CC.CC. como el MCB participaron activamente desde un primer momento en los distintos encuentros campesinos que se celebraron a lo largo de 1976, dando continuidad al primer encuentro celebrado en Tudela de Duero, y por ello fueron dos de las organizaciones que fundaron la COAG en diciembre de ese mismo año ${ }^{112}$.

\footnotetext{
107 Alonso et al. (1976): 11-15.

108 “Maxi” Rodríguez, sindicalista agrario», El País, 24-6-1989.

109 Entrevista a Rafael Martín y José Antonio Arias, en Falces Yoldi (2006): 62-65.

110 AHPV, Gobierno Civil, Caja 1706, Carp. 1.

111 «Escrito-estudio sobre los problemas de la cebada elaborado por un grupo de agricultores", El Norte de Castilla, 7-5-1976.

112 Véase la primera acta de la COAG, reproducida en Falces Yoldi (2006): 42, donde se hace referencia al «Movimiento Campesino [de Base] de Valladolid» y a las «Comisiones Campesinas de Castilla y León».
} 
No obstante, las reuniones celebradas en Medina de Rioseco no solo sirvieron para consolidar el MCB, y con él posteriormente la COAG, sino que también permitieron articular una pequeña organización agraria socialista en Valladolid. En efecto, uno de los más asiduos asistentes a aquellas reuniones fue Ángel Fernández, un agricultor riosecano afiliado al PSOE y a la UGT y responsable de la organización en la clandestinidad de un pequeño foco socialista en Medina de Rioseco y la comarca de Tierra de Campos ${ }^{113}$. Por ello, muy probablemente estuvo detrás de algunas acciones de oposición que se produjeron en Medina de Rioseco durante los últimos meses de la dictadura, como fue la pegada de pegatinas de la UGT en diversas puertas y escaparates de la localidad ocurrida en el verano de $1975^{114}$. Ya en 1976, fue uno de los organizadores del mitin que celebró el PSOE en Medina de Rioseco el día 12 de septiembre, uno de los primeros actos públicos celebrados por el PSOE en la provincia tras la dictadura, y en el que participaron, además del propio Ángel Fernández, Gregorio Peces-Barba, Ciriaco de Vicente y Juan Colino ${ }^{115}$. Su actividad sindical en el medio rural le llevó a ser nombrado en el mes de octubre secretario general de la Federación de Trabajadores de la Tierra (FTT) de la UGT ${ }^{116}$, cargo que ocupó hasta 1980 cuando, por desavenencias con el sindicato y el partido, dimitió como secretario general de la FTT-UGT ${ }^{117}$ y, poco después, fue expulsado del PSOE ${ }^{118}$.

A pesar del importante papel que tuvo Ángel Fernández en la reorganización de la FTT-UGT a nivel nacional, el sindicato agrario socialista tuvo una presencia residual tanto en la provincia de Valladolid como en el conjunto de Castilla y León ${ }^{119}$. Con todo, eso no impidió que, en determinadas coyunturas, sobre todo antes de que se consolidaran otras organizaciones agrarias de clase, Ángel Fernández se erigiera en portavoz de los sectores agrarios progre-

113 Entrevista a Juan Colino. Valladolid, 2-7-2019.

114 AHPV, Gobierno Civil, Caja 1703, Carp. 6, 10-6-1975 y 18-8-1975.

115 «Hoy, a las doce, acto socialista en Medina de Rioseco», El Norte de Castilla, 12-91976 y "El PSOE tiene vocación de gobernar», El Norte de Castilla, 14-9-1976. También en AHPV, Gobierno Civil, Caja 1706, Carp. 3, 7-9-1976.

116 «Ángel Fernández Pérez, de Medina de Rioseco, elegido secretario general de la Federación de Trabajadores de la Tierra», El Norte de Castilla, 19-10-1976. Sobre los primeros años de andadura de la FTT y la actividad de Ángel Fernández al frente de la misma, véase Herrera González de Molina (2007): 126-140.

117 Herrera González de Molina (2007): 256.

118 «El PSOE de Valladolid expulsa al antiguo secretario general de FTT-UGT, Ángel Fernández», El Norte de Castilla, 17-6-1980.

119 En 1981 tenía menos de cincuenta afiliados en Valladolid, y menos de trescientos en toda Castilla y León. Herrera González de Molina (2007): 392-393. 
sistas de Valladolid, tal y como sucedió durante la «guerra de los tractores» de febrero-marzo de 1977, cuando reivindicó públicamente el desmantelamiento del sindicalismo agrario verticalista:

Ni las Cámaras Oficiales Agrarias, ni las Hermandades, cuentan con la representatividad, con la capacidad de actuación como para intervenir con eficacia frente al hecho de unos precios políticos que no se corresponden con los costos reales de producción. En las últimas semanas, he recorrido doce provincias, y he comprobado hasta qué punto los agricultores necesitan unas estructuras adecuadas, no marcadas por intereses creados. Urge la unidad de todos en torno a unos sindicatos libres que defiendan a los trabajadores del campo ${ }^{120}$.

Como ya hemos visto que sucedió con el sindicalismo agrario conservador, la «guerra de los tractores» fue el punto de inflexión que impulsó la actividad de los sindicatos agrarios de clase, especialmente de las UAG vinculadas a la $\mathrm{COAG}^{121}$, que también vivieron ese proceso de federaciones, fusiones, absorciones, etc., que simplificó el panorama sindical agrario del país tras la aprobación de la ley de libertad sindical de abril de $1977^{122}$.

En efecto, ya el 27 de febrero de 1977, cuando las carreteras de León y Burgos estaban ocupadas por los tractores, por iniciativa de la Unión de Campesinos Zamoranos se conformó la Coordinadora Regional de Organizaciones Campesinas de Castilla y León, que agrupaba a las distintas asociaciones agrarias de Ávila, Burgos, Palencia, Soria, Segovia, Valladolid y Zamora integradas en la COAG, con el objetivo de promover en la cuenca del Duero "un sindicato campesino que sea democrático, unitario, independiente y asambleario" y denunciando "el intento de manipulación de este movimiento [la "guerra de los tractores»] por parte de la COSA» ${ }^{123}$.

Por esas mismas fechas, por mediación de esta nueva coordinadora regional, se produjo la fusión de CC.CC. y MCB, las dos organizaciones vallisoletanas integradas en la COAG, surgiendo una nueva organización: la Unión Campesina de Valladolid (UCV). Las primeras informaciones documentales sobre esta nueva organización datan de finales del mes de marzo, cuando la UCV distribuyó por diversos pueblos de la provincia un manifiesto donde

120 «Más allá del problema de las patatas está la necesidad de reformar las estructuras agrarias», El Norte de Castilla, 24-2-1977.

121 Moyano Estrada (1984): 206-208 y Fuente Blanco (1990): 89.

122 Moyano Estrada (1984): 170.

123 «Constitución de la Coordinadora Regional de Organizaciones Campesinas de Castilla y León", El Norte de Castilla, 1-3-1977. 
solicitaba la dimisión de los cargos sindicales agrarios, alcaldes y corporaciones y jueces de paz de los pueblos de la provincia como acto de protesta ante la represión ejercida por las fuerzas del orden público durante la "guerra de los tractores ${ }^{124}$. Del mismo modo que sucedió con el resto de asociaciones agrarias del país, la UCV aprovechó la ley de libertad sindical de abril de 1977 para legalizarse el 2 de mayo de ese mismo año, autocalificándose como «un movimiento campesino de base desligado de los partidos políticos, si bien en su seno caben todas las ideologías» y desmintiendo "la acusación de «comunistas» que, según los representantes provisionales de esta asociación les habían hecho los «caciques"»", defendiendo que «su funcionamiento será plenamente democrático, siendo las asambleas órganos decisorios» ${ }^{125}$. De este modo, la UCV se convertía en la primera OPA vallisoletana en regularizar su situación y, a partir de entonces, inició una intensa campaña sindical que le llevó a celebrar multitud de reuniones, asambleas y mítines en decenas de pueblos para presentar su programa agrario y captar afiliados ${ }^{126}$.

A nivel regional, a pesar de su importante labor en la creación de la UCV, la Coordinadora Regional de Organizaciones Campesinas de Castilla y León tuvo escaso recorrido y terminó disolviéndose. Por ello, un año más tarde, a finales de mayo de 1978, las UAG de las distintas provincias de la cuenca del Duero, incluyendo ya León y Salamanca, volvieron a reunirse en el Instituto Rural El Pino de Valladolid para conformar la Coordinadora Regional de Castilla y León (CORE), con el objetivo de crear un «ente intermediario entre las Uniones [de Campesinos] y la Coordinadora Nacional [COAG]» y erigirse «en portavoz de los intereses de la región y en baluarte de defensa de la agricultura del Duero ${ }^{127}$.

Junto a la UCV y la minoritaria FTT-UGT, el panorama del sindicalismo agrario de clase de la provincia de Valladolid se complementó con la Unión de Ganaderos de Valladolid (UGV), creada en septiembre de 1978 de la mano de Fernando Moráis de la Horra, quien, como vimos, estaba vinculado al PTE y ya fue impulsor de las CC. CC. en la provincia ${ }^{128}$. El objetivo

124 AHPV, Gobierno Civil, Caja 1408, Carp. 17, 27-3-1977.

125 «La Unión Campesina de Valladolid cumplió el trámite de legalización», El Norte de Castilla, 3-5-1977.

126 Según Maxi Rodríguez, entonces secretario de la UCV, durante la segunda mitad de 1977 celebraron reuniones en más de ochenta pueblos de la provincia. «Reunión del secretariado de Unión Campesina de Valladolid», El Norte de Castilla, 11-12-1977.

127 «Hoy se constituirá la Coordinadora Regional de Castilla y León», El Norte de Castilla, 16-4-1978.

128 Entrevista a Honorino Fernández. Peñafiel (Valladolid), 22-7-2019. 
de esta nueva asociación agraria, que se definía como «unitaria, democrática e independiente», era "luchar por los intereses de los pequeños y medianos ganaderos» y vincularse a la COAG ${ }^{129}$. Por ello, la UCV y la UGV tuvieron contactos frecuentes para unificar su acción y reivindicaciones, e incluso se produjeron conversaciones para una posible fusión que no se llegó a concretar. Finalmente, con el paso del tiempo, en la UGV se impusieron los intereses profesionales sobre las posiciones ideológicas, y la organización terminará por integrarse en AEPA en $1982^{130}$.

\section{CONCLUSIONES}

El presente texto nos muestra que, tras la muerte del dictador, se produjo en la provincia de Valladolid una eclosión de la actividad sindical agraria que se tradujo en la creación de infinidad de asociaciones agrarias de diversa ideología y tipo.

En síntesis, desde los sectores agrarios conservadores primero se creó ARA y, poco más tarde, APAG y AEPA, la primera vinculada a los antiguos dirigentes del sindicalismo vertical, y la segunda impulsada por grupos de agricultores críticos con los dirigentes sindicales durante el tardofranquismo. En este mismo ámbito ideológico también surgió AGGR, una asociación para la defensa de los intereses ganaderos, y se refundó el SR, un sindicato sectorial que durante la dictadura había mantenido amplia independencia de acción. Desde los sectores agrarios progresistas se crearon, todavía en la clandestinidad, las CC.CC., vinculadas al PTE, y el MCB, impulsado por sectores progresistas de la Iglesia católica y el PCE. Ya en 1977, estas dos organizaciones se fusionaron para crear la UCV. Otras organizaciones progresistas fueron la pequeña sección provincial de la FTT-UGT y la UGV, un sindicato ganadero que, a pesar de unos orígenes cercanos al PTE, terminó integrándose en AEPA.

Tras su creación y legalización, las distintas asociaciones agrarias vallisoletanas iniciaron una frenética actividad sindical que las llevó a entablar contactos con otras asociaciones similares para crear federaciones y confederaciones de ámbito regional y nacional. Así, a nivel regional diversas asociaciones agrarias conservadoras, incluidas APAG y AEPA, fundaron la Federación de Agricultores y Ganaderos de la Cuenca del Duero. Mientras,

129 «Nos hemos agrupado para defender los intereses de los ganaderos pequeños y medianos", El Norte de Castilla, 9-9-1978.

130 Falces Yoldi (2006): 125. 
las asociaciones agrarias progresistas crearon, primero, la Coordinadora Regional de Organizaciones Campesinas de Castilla y León y, después, la CORE. Del mismo modo, a nivel nacional las asociaciones agrarias vallisoletanas participaron en la fundación de algunas de las grandes centrales sindicales agrarias que dominaron el panorama sindical del país entre finales de los setenta e inicios de los ochenta: AEPA fue fundadora de la CNAG; APAG de UFADE, y las CC.CC. y el MCB de COAG, organización en la que posteriormente se integró la UCV.

En definitiva, el análisis la lluvia de siglas que tuvo lugar en el campo vallisoletano durante la segunda mitad de los ańos setenta nos permite sacar, en esencia, tres conclusiones. En primer lugar, y del mismo modo que han mostrado otras investigaciones similares realizadas en los últimos años, permite certificar que en España se produjo una notable movilización agraria tras el fin de la dictadura franquista, lo que es una clara muestra de que la sociedad rural espańola no fue ajena al acontecer político de su tiempo, sino que tuvo un papel activo en el desarrollo del proceso democratizador que vivió el país durante la Transición. En segundo lugar, permite mostrar que esa movilización agraria también tuvo un notable eco en la cuenca del Duero, como muestra la proliferación de sindicatos agrarios que se produjo en la provincia de Valladolid. En tercer lugar, permite mostrar que esta sindicalización agraria no solo fue impulsada por organizaciones y asociaciones progresistas, como han señalado la mayoría de investigaciones que han afrontado este tema de estudio, sino que también fue promovida por la actividad sindical de sectores conservadores que buscaron definir un espacio propio dentro del nuevo panorama sindical agrario que se abrió con el advenimiento de la democracia.

\section{Bibliografía}

Abad, C. y Naredo, J. M. (1997). Sobre la «modernización» de la agricultura española (19401995). En C. Gómez y J. J. González (coords.). Agricultura y sociedad en la España contemporánea (pp. 249-316). Madrid: Centro de Investigaciones Sociológicas; Ministerio de Agricultura, Pesca y Alimentación.

Alonso, V. L., Calzada, J., Huerta, J. R., Langreo, A. y Viñas, J. S. (1976). Crisis agrarias y luchas campesinas, 1970-1976. Madrid: Editorial Ayuso.

Ariza, J. (1976). Comisiones Obreras. Barcelona: Avance.

Arnalte, E. y Ceña, F. (1993). La agricultura y la política agraria en España durante el período de transición democrática. Agricultura y Sociedad, 68-69, 289-312. Disponible en: https://bit.ly/2Zk7KSZ. 
Arribas, J. M. y González, J. J. (1984). El sindicalismo de clase en la agricultura familiar (Las Cuencas del Ebro y del Duero). Agricultura y Sociedad, 31, 121-151. Disponible en: https://bit.ly/2R7rzZ7.

Baraja, E. (1994). La industria azucarera y el cultivo remolachero del Duero en el contexto nacional. Madrid: Ministerio de Agricultura, Pesca y Alimentación.

Bernal, A. M. (2001). Sindicalismo jornalero y campesino en España (1939-2000). En A. López y M. Ortiz (coords.). Entre surcos y arados. El asociacionismo agrario en la España del siglo XX (pp. 17-45). Cuenca: Universidad de Castilla-La Mancha.

Berzal de la Rosa, E. (2001). De la sopa de letras a la madurez política. En E. Berzal de la Rosa (coord.). Crónica de Valladolid, 1936-2000. La historia de la provincia de Valladolid desde la Guerra Civil hasta nuestros días (pp. 274-289). Valladolid: El Mundo Valladolid.

- (2007). Sotanas rebeldes. Contribución cristiana a la transición democrática. Valladolid: Diputación de Valladolid.

(2018). Iglesia, sociedad y democracia. El clero progresista como factor deslegitimador del franquismo en Castilla y León, 1966-1975. Studia Histórica. Historia Contemporánea, 36, 257-285. Disponible en: http://dx.doi.org/10.14201/shhc201836257285.

Cabana Iglesia, A. (2019). Transitar la Transición: mundo rural y cultura democrática. En R. Quirosa-Cheyrouze y E. Martos (eds.). La Transición desde otra perspectiva. Democratización y mundo rural (pp. 149-168). Madrid: Sílex.

Cruz Artacho, S. (2001). El «hermano pobre» de la historia social española. Algunas consideraciones sobre el conflicto campesino en la Historia Contemporánea. En S. Castillo y R. Fernández (coords.). Historia social y ciencias sociales. Actas del IV Congreso de Historia Social de España (pp. 245-289). Lérida: Milenio Actas.

Díaz, A. y Taboada, A. (2014). Sindicalismo nacionalista en el rural gallego del tardofranquismo y la Transición (1973-1978): Discurso y práctica para la democracia desde el campo. Historia, Trabajo y Sociedad, 5, 101-117. Disponible en: https://bit.ly/3iaTIuf.

Díaz Geada, A. (2011). O campo en movemento. O papel do sindicalismo labrego no rural galego do tardofranquismo e da transición (1964-1986). Santiago de Compostela: Universidad de Santiago de Compostela.

Falces Yoldi, J. I. (2006). Haciendo Unión, 1976-2004. Valladolid: Unión de Campesinos COAG de Valladolid.

Ferrer Gálvez, F. (2019). El sindicalismo «reformista» en la agricultura intensiva. Desarrollo y consolidación del Centro Nacional de Jóvenes Agricultores (CNJA) en Almería. Historia Actual Online, 50 (3), 51-64. Disponible en: https://doi.org/10.36132/hao. vi50.1779.

Ferrer González, C. (2018). El PSUC y el trabajo en el campo. El movimiento campesino entre el franquismo y la Transición. En D. Lanero Táboas (ed.). El disputado voto de los labriegos. Cambio, conflicto y continuidad politica en la España rural (1968-1986) (pp. 111-134). Granada: Comares.

Fuente Blanco, G. de la (1990). Los sindicatos agrarios: nuevos modelos organizativos en la España comunitaria. Madrid: Universidad Complutense de Madrid. 
Fuentes, M. C. y Cobo, F. (2016). La tierra para quien la trabaja: los comunistas, la sociedad rural andaluza y la conquista de la democracia (1956-1983). Granada: Universidad de Granada.

Gallego, J. A. (1987). Historia General de España y América. La época de Franco. Tomo XIX-2. Madrid: Rialp.

Gil García, P. (2005). Las Hermandades Sindicales de Labradores y Ganaderos (1944-1977). Cuenca: Universidad de Castilla-La Mancha.

Gómez Benito, C. (2001). El asociacionismo agrario en la agricultura familiar española. En A. López y M. Ortiz (coords.). Entre surcos y arados. El asociacionismo agrario en la España del siglo XX (pp. 47-75). Cuenca: Universidad de Castilla-La Mancha.

González, J. J. (1984). Entrevista a Adolfo Sánchez Martín. Agricultura y Sociedad, 31, 199-221. Disponible en: https://bit.ly/35mhfVL.

González Fernández, A. (2015). Los empresarios ante los cambios económicos y sociales. En G. Sánchez Recio (coord.). Eppure si muove. La percepción de los cambios en España (pp. 101-119). Madrid: Biblioteca Nueva.

- (2019). El campo se mueve: modernización y dinámicas de protesta en tiempos de dictadura en la Europa Mediterránea. En R. Quirosa-Cheyrouze y E. Martos (eds.). La Transición desde otra perspectiva. Democratización y mundo rural (pp. 73-92). Madrid: Sílex.

González de Molina, M. (2008). Algunas reflexiones sobre el mundo rural y los movimientos campesinos en la Historia contemporánea española. En A. Rivera, J. M. Ortiz de Ortuño y J. Ugarte (eds.). Movimientos sociales en la España Contemporánea (pp. 97-126). Madrid: Abada Editores.

Gutiérrez Hurtado, F. J. (1987). Agricultura y capitalismo. Valladolid, 1939-1982. Valladolid: Universidad de Valladolid.

Herrera, A. y Markoff J. (2013). Democracia y mundo rural en España. Ayer, 89. Disponible en: http://revistaayer.com/anteriores/127.

Herrera González de Molina, A. (2007). La construcción de la democracia en el campo (19751988). El sindicalismo agrario socialista en la Transición española. Madrid: Ministerio de Agricultura, Pesca y Alimentación.

Lanero, D. y Míguez, A. (2013). Introducción. ¿Lejos de la apatía?: politización y movimientos sociales en la Espańa rural del final del franquismo y la Transición (19681982): un estado de la cuestión. En D. Lanero (ed.). Por surcos y calles. Movilización social e identidades en Galicia y País Vasco (1968-1980) (pp. 7-31). Madrid: La Catarata.

Langreo, A. (1996). Del campesino al empresario agrario: los conflictos actuales del medio rural. En M. A. García de León (ed.). El campo y la ciudad (Sociedad rural y cambio social) (pp. 47-77). Madrid: Ministerio de Agricultura, Pesca y Alimentación.

Martín García, O. J. (2010). Oportunidades, amenazas y percepciones colectivas en la protesta contra el franquismo final, 1973-1976. Historia Social, 67, 51-67. Disponible en: https://bit.ly/3h7dx4f.

Martínez Pérez, D. (2015). Construyendo la democracia. Tardofranquismo, transición política y la cuestión autonómica en la provincia de León (1962-1984) [tesis doctoral]. Universidad de León. Disponible en: https://buleria.unileon.es/handle/10612/5903. 
Miranda Rubio, F. (1994). Los procuradores de representación familiar en la novena legislatura franquista (1967-1971). Principe de Viana, 203, 615-638. Disponible en: http:// www.culturanavarra.es/uploads/files/PV203-pagina0615.pdf.

Moyano Estrada, E. (1984). Corporatismo y agricultura. Asociaciones profesionales y articulación de intereses en la agricultura española. Madrid: Instituto de Estudios Agrarios, Pesqueros y Alimentarios.

- (1988). Sindicalismo y politica agraria en Europa. Madrid: Ministerio de Agricultura, Pesca y Alimentación.

- (1997). Acción colectiva y organizaciones profesionales agrarias en España. En C. Gómez y J. J. González (coords.). Agricultura y Sociedad en la España contemporánea (pp. 773-795). Madrid: Centro de Investigaciones Sociológicas; Ministerio de Agricultura, Pesca y Alimentación.

- (2008). Capital social y acción colectiva en el sector agrario. Revista Española de Sociologia. 10, 15-37. Disponible en: https://recyt.fecyt.es/index.php/res/article/view/65074.

Orrasco García, E. (2010). ACOR. Un sueño hecho realidad. Valladolid: Eusebio Orrasco García.

Ortiz Heras, M. (1992). Las Hermandades de Labradores en el franquismo: Albacete, 19431977. Albacete: Instituto de Estudios Albaceteños.

Quirosa-Cheyrouze, R. (2016). Las organizaciones políticas en la transición a la democracia. De la sopa de letras al predominio socialista. En M. Ortiz Heras (coord.). La transición se hizo en los pueblos. El caso de la provincia de Albacete (pp. 75-110). Madrid: Biblioteca Nueva.

— y Martos, E. (2019) (eds.). La Transición desde otra perspectiva. Democratización y mundo rural. Madrid: Sílex.

Sabio Alcutén, A. (2001). Labrar democracia y sembrar sindicalismo. La Unión de Agricultores y Ganaderos de Aragón, 1975-2000. Zaragoza: UAGA.

- (2006). Cultivadores de democracia. Politización campesina y sindicalismo agrario progresista en España, 1970-1990. Historia Agraria. 38, 75-102. Disponible en: http:// www.historiaagraria.com/FILE/articulos/albertosabio38.pdf.

- (2019). Tractores no amarillos. Protesta y politización de la explotación familiar agraria en España, 1970-1980. En R. Quirosa-Cheyrouze y E. Martos (eds.). La Transición desde otra perspectiva. Democratización y mundo rural (pp. 213-234). Madrid: Sílex.

Serrano Blanco, L. (2006). Aportaciones de la Iglesia a la democracia desde la diócesis de Valladolid, 1959-1979. Salamanca: Universidad Pontificia de Salamanca. 